\title{
Report of Lutzomyia longipalpis (Lutz \& Neiva, 1912) (Diptera: Psychodidae: Phlebotominae) in a cutaneous-leishmaniasis-endemic area of Panama
}

\author{
Anayansi Valderrama ${ }^{1,3} /{ }^{+}$, Mara Garcia Tavares ${ }^{1}$, José Dilermando Andrade Filho \\ 'Departamento de Biologia Geral, Universidade Federal de Viçosa, Viçosa, MG, Brasil \\ ${ }^{2}$ Centro de Referência Nacional e Internacional para Flebotomíneos/Coleção de Flebotomíneos, Instituto René Rachou-Fiocruz, \\ Belo Horizonte, MG, Brasil ${ }^{3}$ Instituto Conmemorativo Gorgas de Estudios de la Salud, Panamá, Panamá
}

Lutzomyia longipalpis is the primary vector of the parasite responsible for visceral leishmaniasis in the Americas. In the present study, Lu. longipalpis was found in a domiciliary area in Limón, a district in Capira, a region in which cutaneous leishmaniasis is endemic in Panama. Previously, this species has been found in a humid forest in this same region. Finding Lu. longipalpis in domiciliary areas indicates that this species may be adapting to new habitats and that it may play a role in the transmission of leishmaniasis in Panama.

Key words: Lutzomyia longipalpis - cutaneous leishmaniasis - visceral leishmaniasis - leishmania vectors - Panama

Lutzomyia longipalpis (Lutz \& Neiva, 1912) (Diptera: Phlebotominae) is the primary vector of the parasite that causes visceral leishmaniasis in the Americas (Young \& Duncan 1994). Leishmaniasis is a disease that principally affects the liver and the spleen. In Panama, approximately 3,000 cases of leishmaniasis per year are registered by the Ministry of Health and by the Gorgas Institute. However, the possibility of underreporting must be considered because the communities in which leishmaniasis is most common are far from health centres (Miranda et al. 2009).

Despite the medical relevance, the taxonomic status of Lu. longipalpis has not yet been defined. Studies carried out by Mangabeira (1969) have demonstrated that male specimens of Lu. longipalpis from the states of Pará and Ceará (Brazil) exhibit morphological differences in the third and fourth abdominal tergites. Later, several morphological and genetic analyses revealed significant differences among Brazilian populations and those distributed in Central America, Colombia and Venezuela, which led to the proposition of the existence of a species complex (Ward et al. 1983, Lanzaro et al. 1993, Arrivillaga \& Feliciangeli 2001, Bauzer et al. 2007, Maingon et al. 2008).

The existence of the Lu. longipalpis complex is very important in the epidemiology of leishmaniasis. Zeledón et al. (1989) and Warburg et al. (1994) demonstrated that the transmission of Leishmania infantum chagasi by Lu. longipalpis in Brazil and Colombia results in visceral infections, whereas the transmission of the same parasite by $L u$. longipalpis in Costa Rica results in nonulcerative lesions. Comparative studies on the saliva

Financial support: SENACYT (COL09-008)

+ Corresponding author: anayvald@yahoo.com

Received 12 May 2011

Accepted 22 September 2011 of these populations of Phlebotominae revealed differences in the chemical composition and the amount of maxadilan affect the proliferation of Leishmania and, consequently, the development of the disease (Warburg et al. 1994, Lanzaro et al. 1999).

The presence of $\mathrm{Lu}$. longipalpis in Panamanian forests was first reported in the 1960s (Theodor 1965, Christensen 1972). Currently, however, there is little knowledge of its distribution, occurrence and participation in the transmission of leishmaniasis in Panama. The present study reports, for the first time, the occurrence of $L u$. longipalpis in a domiciliary area in a region in Panama in which cutaneous leishmaniasis is endemic.

The sampling was carried out in June and August 2010 in Limón, the Campana region, the district of Capira, the province of Panama, in the Republic of Panama. This locality is situated at $8^{\circ} 41^{\prime} 14^{\prime \prime} \mathrm{N} 79^{\circ} 54^{\prime} 3^{\prime \prime} \mathrm{W}$ at an elevation of $506 \mathrm{~m}$. According to Köepper's classification, the climate in the region is AW tropical wet and dry.

Specimens of Phlebotominae fauna were collected with the help of CDC light traps (Sudia \& Chamberlain 1962) using an octanol solution as a supplemental mosquito attractant. The traps were installed in domestic and peridomestic environments at a height of $1.5 \mathrm{~m}$ and the collection period lasted $12 \mathrm{~h}(06: 00 \mathrm{pm}-06: 00 \mathrm{am})$ for three consecutive nights. The captured individuals were placed on glass slides with the use of Berlese's medium for clarification and identification. The specimens were identified by José Dilermando Andrade Filho (National and International Reference Center for Phlebotomine Sand Flies, Belo Horizonte, MG, Brazil) using the scheme of Young and Duncan (1994).

Five females of $\mathrm{Lu}$. longipalpis were collected in June, three inside a house and two in a peridomestic area, close to a henhouse. Two months later, four females and two males were captured in the same peridomestic area. Lutzomyia gomezi, Lutzomyia panamensis and Lutzomyia trapidoi, other species implicated as cutaneous leishmaniasis vectors, were also captured in the CDC light 
traps. The ability of Lu. longipalpis to adapt to changing environments has been observed in other countries (Souza et al. 2009, Acardi et al. 2010). The presence of $\mathrm{Lu}$. longipalpis in domiciliary areas demonstrates that this species can easily adapt to domiciles and adjacent areas, increasing the risk of transmission of leishmaniasis in this region. It must also be highlighted that $L u$. longipalpis was captured in an area where there was a small population. According to the records of the Ministry of Health, most of these people have already presented clinical manifestations of cutaneous leishmaniasis.

Four specimens of Lu. longipalpis were previously collected in Panama, from the forest of the Altos de Campana National Park (Garcés et al. 1999, Valderrama et al. 2008). This national park is a wild area protected by the environmental authorities and is located $16 \mathrm{~km}$ from the community of Limón. Therefore, the presence of $\mathrm{Lu}$. longipalpis individuals near and inside a home in Limón suggests that this species is adapting to the degraded forest environment, possibly as the result of the search for new sources of food and shelter.

Limón is the oldest area of endemic transmission of cutaneous leishmaniasis in Panama. The occurrence number of this disease in this region is 15 cases per year, according to records of the Ministry of Health for 2009, and $95 \%$ of the people infected are non-residents.

It must be stressed that there are no records of visceral leishmaniasis in Panama despite the presence of various mammalian reservoirs of Le. infantum chagasi in South America (Rangel \& Lainson 2003). In fact, it is common to see several sick dogs roaming in Limón. Given that these dogs could be infected with Leishmania parasites, these dogs could increase the risk of the spread of this disease. However, Zeledón et al. (1989) demonstrated that patients infected with Le. infantum chagasi by $L u$. longipalpis in Costa Rica presented non-ulcerative lesions. In addition, Ponce et al. (1991) observed patients with clinical manifestations of both visceral and cutaneous leishmaniasis in the same transmission focus in Honduras. These reports suggest that the transmission of Le. infantum chagasi by the species Lu. longipalpis in Central America only results in cutaneous lesions.

However, the diagnosis of patients with cutaneous leishmaniasis through conventional tests (Montenegro test) is limited and has no specificity to differentiate the Leishmania species (Miranda et al. 2009). Thus, there have been discussions about the cases of cutaneous leishmaniasis detected in Limón as to whether the infections are really caused by Leishmania spp transmitted by Phlebotominae sand flies, vectors of cutaneous leishmaniasis recorded in Panama or by species of Leishmania transmitted by Lu. longipalpis, as observed by Zeledón et al. (1989) and Ponce et al. (1991).

Based on the observations reported and on the presence of Lu. longipalpis in Limón, a region in which cutaneous leishmaniasis is endemic in Panama, further studies focused on the ecological and epidemiological factors related to infection caused by Leishmania spp are needed. The assessment of Lu. longipalpis as a possible vector of leishmaniasis in Limón in particular should be verified because this is an ecotourism region.
Therefore, the detection of Lu. longipalpis in houses in areas degraded by deforestation demonstrates the need to intensify entomological surveillance, to constantly monitor the vector species and to evaluate the effect of human activities on sand fly populations and their wild hosts. Further, it is necessary to implement specific diagnostic techniques to differentiate the species of Leishmania and implement adequate control measures.

\section{REFERENCES}

Acardi SA, Liotta DJ, Santini MS, Romagosa CM, Salomón OD 2010. Detection of Leishmania infantum in naturally infected Lutzomyia longipalpis (Diptera: Psychodidae: Phlebotominae) and Canis familiaris in Misiones, Argentina: the first report of a PCR-RFLP and sequencing-based confirmation assay. Mem Inst Oswaldo Cruz 105: 796-799.

Arrivillaga JC, Feliciangeli MD 2001. Lutzomyia pseudolongipalpis: the first new species within the longipalpis (Diptera: Psychodidae: Phlebotominae) complex from La Rinconada, Curarigua, Lara state, Venezuela. J Med Entomol 38: 783-790.

Bauzer LG, Souza NA, Maingon RD, Peixoto AA 2007. Lutzomyia longipalpis in Brazil: a complex or a single species? A mini-review. Mem Inst Oswaldo Cruz 102: 1-12.

Christensen HA 1972. Check list of the phlebotomine sandflies (Diptera: Psychodidae) of Panama including two species not previously reported. Mosq News 32: 88-89.

Garcés P, Araúz E, Morales Z 1999. Determinación de Phlebotominae: Lutzomyia spp, en un área boscosa del Parque Nacional Altos de Campana, Distrito de Capira, Provincia de Panamá. Scientia 2: 35-47.

Lanzaro GC, Lopes AHCS, Ribeiro JMC, Shoemaker CB, Warburg A, Soares M, Titus RG 1999. Variation in the salivary peptide, maxadilan, from species in the Lutzomyia longipalpis complex. Insect Mol Biol 8: 267-275.

Lanzaro GC, Ostrovska K, Herrero MV, Lawyer PG, Warburg A 1993. Lutzomyia longipalpis is a species complex: genetic divergence and interspecific hybrid sterility among three populations. Am J Trop Med Hyg 48: 839-847.

Maingon RD, Ward RD, Hamilton JG, Bauzer LG, Peixoto AA 2008. The Lutzomyia longipalpis species complex: does population sub-structure matter to Leishmania transmission? Trends Parasitol 24: 12-17.

Mangabeira O 1969. Sôbre a sistemática e biologia dos Phlebotomus do Ceará. Rev Bras Malariol D Trop 21: 3-25.

Miranda A, Carrasco R, Paz H, Pascale JM, Samudio F, Saldaña A, Santamaría G, Mendoza Y, Calzada J 2009. Molecular epidemiology of American tegumentary leishmaniasis in Panama. Am J Trop Med Hyg 81: 565-571.

Ponce C, Ponce E, Morrison A, Cruz A, Kreutzer R, McMahonPratt D, Neva F 1991. Leishmania donovani chagasi: new clinical variant of cutaneous leishmaniasis in Honduras. Lancet 337: 67-70.

Rangel EF, Lainson R 2003. Ecologia das leishmanioses: transmissores de leishmaniose tegumentar americana. In EF Rangel, $\mathrm{R}$ Lainson (eds.), Flebotomíneos do Brasil, Fiocruz, Rio de Janeiro, p. 291-310.

Souza GD, Santos E, Andrade Filho JD 2009. The first report of the main vector of visceral leishmaniasis in America, Lutzomyia longipalpis (Lutz \& Neiva) (Diptera: Psychodidae: Phlebotominae), in the state of Rio Grande do Sul, Brazil. Mem Inst Oswaldo Cruz 104: 1181-1182. 
Sudia WD, Chamberlain RW 1962. Battery operated light trap, an improved model. Mosq News 22: 126-129.

Theodor O 1965. On the classification of American Phlebotominae. J Med Entomol 2: 171-197.

Valderrama A, Herrera M, Salazar A 2008. Relación entre la composición de especies del género de Lutzomyia França (Diptera: Psychodidade, Phlebotominae) y los diferentes tipos de bosques en Panamá. Acta Zool Mex 24: 67-78.

Warburg A, Saraiva E, Lanzaro GC, Titus R, Neva F 1994. Saliva of Lutzomyia longipalpis sibling species differs in its composition and propensity to enhance leishmaniasis. Phil Trans Roy Soc Lond 345: 223-230.
Ward RD, Ribeiro AL, Ready PD, Murtagh A 1983. Reproductive isolation between different forms of Lutzomyia longipalpis (Lutz \& Neiva), (Diptera: Psychodidae), the vector of Leishmania donovani chagasi Cunha \& Chagas, and its significance to kala-azar distribution in South America. Mem Inst Oswaldo Cruz 78: 269-280.

Young DG, Duncan MA 1994. Guide to the identification and geographic distribution of Lutzomyia sandflies in Mexico, the West Indies, Central and South America (Diptera: Psychodidae). Mem Amer Entomol Inst 54: 1-881.

Zeledón R, Hidalgo H, Víquez A, Urbina A 1989. Atypical cutaneous leishmaniasis in a semiarid region of north-west Costa Rica. Trans R Soc Trop Med Hyg 83: 786. 